Vantage: Journal of Thematic Analysis

ISSN: 2582-7391

A Multidisciplinary Publication of Centre for Research,

Maitreyi College, University of Delhi

April 2021, Volume 2, Issue 1

Editorial

\title{
COVID-19: Impact, Implications and Path Ahead
}

The first human case of COVID-19 was reported on November 17, 2019 from Wuhan district in China and the novel coronavirus outbreak was declared a global pandemic on March 11, 2020. This is one of the worst calamities faced by humans with the pandemic spreading to 6 continents and over 219 countries with 134 million cases and 2.91 million deaths reported worldwide as on April 9, 2021 (John Hopkins, CSSE, 2021). It served as the greatest leveller of our times, as the virus affected the developed and developing world and the rich and poor alike. It brought to the fore the fragility of healthcare systems across the world. Even developed countries like the US and Italy, with allegedly the best healthcare infrastructure, crumbled. As Imrana Qadeer asserts in her article, we need to rediscover a public health approach that places human beings centre stage and demands that profits are redefined to include the value of lives and human welfare.

Different nations came up with strategies such as lockdown, social distancing and sanitisation to control the spread of the disease. National lockdowns threatened the economic, social and cultural fabric of the society. It took its toll on the global economy and according to the International Monetary Fund, the economy shrunk by 3.5\% (IMF, January 2021). This is worse than the great depression of the 1930s. Unemployment rates soared and most countries are facing an imminent recession. The lockdown hit hard, especially the unorganised sectors and low-income groups.

The impact of the pandemic on women was multi-layered. On the one hand, women faced the brunt of lockdown both professionally as well as at home. They juggled their jobs and household responsibilities. Unfortunately, what was believed to be the safest place for them became the worst scene of domestic violence. They also faced greater unemployment and there was an increase in the rate of dropout from the labour force 
due to lack of protection by the State. Gender discrimination came to the fore even in fields of scientific research, leadership and governance. On the other hand, the four decades long research of Hungarian biochemist Katalin Kariko formed the basis of the corona vaccine launched by Moderna and Pfizer's-BioNTech (Trouillard, 2020). Interestingly, women also emerged as world class leaders taking charge of the situation. It was observed that female leaders like Jacinda Arden of New Zealand, Taiwan's TsaiIng-Wen and Angela Merkel from Germany displayed exceptional leadership in handling the pandemic as compared to countries with similar per capita GDP, population density, per capita health expenditure, number of tourists, etc. They seemed to be more democratic in their approach and chose to communicate directly with citizens. Perhaps better performance of women leaders could be also attributed to quick and participative decision making and willingness to take risks with their economies rather than human lives by initiating early lockdowns (Garikipati \& Kambhampati, 2020).

Although lockdowns helped control the ravaging pandemic, we also witnessed a large number of cases of depression, anxiety, and loneliness due to social isolation. The articles by Rashi Bhargava and her group, and Manisha Saluja and Aakriti Agarwala, engage with these issues through data drawn from empirical research and through a reading of literary and cinematic texts. They highlight the impact of the pandemic on the mental health of students in particular and society in general.

The pandemic also saw the emergence of certain new norms that would probably bode well for our future. Digital tools and social media have become an increasingly important part of our lives that have facilitated sharing of knowledge and been instrumental in overcoming physical barriers caused by social distancing. Online teaching-learning in schools and colleges became the new norm and transformed the way people think and work. Online education has created the possibility of increased access to education and building a hybrid model of education. Newer opportunities have been created for companies and professionals as remote working turned mainstream. The practice of maintaining better standards of hygiene during the pandemic has become a way of life and may also reduce the burden of other communicable diseases like tuberculosis. 
The pandemic made us creative and innovative and we as a nation moved towards selfreliance. Our scientists developed diagnostic kits for early and accurate detection of corona at reasonable prices to accelerate testing, and indigenous vaccines such as Covaxin not only catered to our country but were also gifted to many other nations across the world. We came up with innovative interventions ranging from multiple ventilator hoses to single ventilator machines, portable ventilator machines, DIY face masks, hand sanitisers, etc. Even trains were converted to makeshift hospital wards and mobile vans converted to testing laboratories to meet the daunting task of diagnosis and treating a multitude of patients. The report by Sanjay Mohan Gupta highlights some of the indigenous technologies and products developed by Defence Research and Development Organization (DRDO), Ministry of Defence, Government of India. Entrepreneurial energies which drove this effort need to be nurtured post pandemic also.

Scientists and medical fraternity from all parts of the world rose to the occasion to develop methods for early and accurate detection of disease as well as strategies for treatment and prevention. It became imperative to share information, knowledge and experience about the pathogen, its genome sequence, mode of transmission and possible interventions to accelerate learning and facilitate rapid progress. This resulted in the birth of a global collaboration-access to COVID-19 tools accelerator (ACT). Researchers responded quickly to emergency situations as speed and severity of the pandemic did not allow the luxury of following traditional testing, trials of new technologies, processes, medicines and vaccines, to name a few. Within a span of a year, more than 300 anti-SARS-CoV-2 candidate vaccines are underway, and around 50 candidate vaccines are undergoing clinical trials. The article by Saima Syeda and Anju Shrivastava explores the various platforms for vaccine development and gives an insight into the vaccine program initiated in India. Nonetheless, it needs to be noted that vaccine development is always associated with rigorous safety evaluation as vaccines are administered to a healthy population as compared to medicines meant for illness and morbidity. Hence, even though administration of vaccines is a necessity at this point of time to return to some degree of normalcy, strict regulations need to be implemented and the data needs to be carefully analysed. 
At the moment, the million dollar question is -"when will the pandemic end or will coronavirus ever be eradicated?" According to a survey conducted by Nature, over 100 immunologists, virologists and infectious disease researchers working on SARS -CoV2 , feel that this is an improbable dream. They reinforce that over time it would become endemic and less threatening. People would become more immune to the virus, either due to natural infection or vaccination and would experience mild symptoms. However, at present and maybe for a year or two, countries need to implement strict measures to control transmission including social distancing, wearing masks in public, use of sanitizers and avoid public gathering. Distinguished American epidemiologist and Director of Center for Infectious Disease Research and Policy (CIDRAP), Michael T. Osterholm warns, that if at this stage, when enough people have not been vaccinated or achieved herd immunity, we abandon precautions, then "the darkest days of the pandemic are still ahead of us" (Philips, 2021).

As Shivcharan Prasad and Ipsita Roy aptly point out in their article, coordination and preparedness are the keys to avoid the most adverse consequences of the pandemic. They talk of the need to strengthen the grassroot healthcare workers. They also emphasize the urgent need to invest in Research and Development and health ecosystems before the next calamity strikes. The need of the hour is to have integrated plans including initiatives by the Government to prevent economic hardships, to ease social tensions, and normalise lives. Active participation of the masses and change of attitudes in all spheres of life will go a long way to steer our life towards normalcy. We need to accept that the pandemic is here to stay and we have to learn to live with it.

\section{REFERENCES}

Garikipati, S., \& Kambhampati, U. S. (2020, August 28). Are women leaders really doing better on coronavirus? The data backs it up. The conversation. Retrieved from: https://theconversation.com/are-women-leaders-really-doing-better-oncoronavirus-the-data-backs-it-up-144809

International Monetary Fund. (2021). Retrieved from https://www.imf.org/en/ Publications/WEO/Issues/2021/01/26/2021-world-economic-outlook-update 
John Hopkins, CSSE (2021). Retrieved from https://coronavirus.jhu.edu/map.html (Apr 8, 2021).

Philips, N. (2021). The coronavirus is here to stay — here's what that means. Nature, 590, 382-384.

Trouillard, S. (2020). Katalin Kariko, the scientist behind the Pfizer Covid-19 vaccine. France 24. Retrieved from: https://www.france24.com/en/americas/ 20201218katalin-kariko-the-scientist-behind-the-pfizer-covid-19-vaccine

How to cite this article: Editorial (2021). COVID-19: Impact, Implications and Path Ahead. Vantage: Journal of Thematic Analysis, 2(1): 1-5.

DOI: https://doi.org/10.52253/vjta.2020.v02i01.01

(C) The Author(s) 2021.

This work is licensed under a Creative Commons Attribution 4.0 International License which permits its use, distribution and reproduction in any medium, provided the original work is cited. 